Received: 11.10 .2018

Revised: 22.02 .2019

Accepted: 22.03 .2019

DOI: $10.17804 / 2410-9908.2019 .2 .006-015$

\title{
A METHOD FOR TESTING THE QUALITY OF WELDED JOINTS ON POLYMERIC PIPES
}

\author{
A. I. Gerasimov ${ }^{\text {a) }}$ and E. V. Danzanova ${ }^{\text {b)* }}$ \\ Institute of Oil and Gas Problems, Siberian Branch of the Russian Academy of Sciences, \\ 1 Oktyabrskaya St., Yakutsk, 677980, Russian Federation \\ a) (iD https://orcid.org/0000-0003-4114-9955 gerasimov2509@ rambler.ru; \\ b) (iD https://orcid.org/0000-0002-3445-0961 dhv4071@ mail.ru \\ *Corresponding author. E-mail: Dhv4071@mail.ru \\ Address for correspondence: 1 Oktyabrskaya St., 677980, Yakutsk, Russian Federation \\ Tel.: +7 (4112) 357293
}

At present, the existing methods for testing the quality of welded joints on polyethylene pipes in the current regulatory documents cannot quantify weld strength. This paper presents research on the development of methods for quantifying the strength of welded joints produced under different welding conditions. Data on the effect of changing one of the welding parameters on the failure stress of the resulting joints are obtained.

Keywords: polyethylene pipe, welded joints, tensile test, welding parameters, failure stress.

\section{Acknowledgment}

The work has been accomplished within the framework of the State Order of the Federal Agency for Scientific Organizations of the Russian Federation (project No. 0377-2016-0004).

\section{References}

1. Korab G.N., Adamenko A.A., Repa V.P. Increasing the reliability of welded joints of plastic pipes made by a heated butt-end tool. Avtomaticheskaya Svarka, 1984, no. 4, pp. 64-65. (In Russian).

2. SP 42-103-2003. Proektirovanie $i$ stroitelstvo gazoprovodov iz polietilenovykh trub $i$ rekonstruktsiya iznoshennykh gazoprovodov [Design and Construction of Gas Pipelines Made of Polyethylene Pipes and Reconstruction of Worn-Out Gas Pipelines: Building Regulation]. Moscow, Polimergaz, FGUP TsPP Publ., 2003, 86 p. (In Russian).

3. Adamenko A.A., Korab G.N., Tarnogorodsky V.P. Improving the quality of plastic pipe joints made by contact heat welding. Avtomaticheskaya Svarka, 1983, no. 3. pp. 51-53 (In Russian). 4. Aksenova G.V., Kashkovskaya E.A. Quality control of welded joints of polyethylene pipes according to the mode of failure under axial tension. Avtomaticheskaya Svarka, 1980, no. 2, pp. 61-63 (In Russian).

5. Krasnikov M.A., Pozhalov Yu.V., Sokolov V.A. Mechanics of failure of butt-welded joints of polyethylene pipes during tensile testing by static loads. Polimergaz, 2011, no. 1, pp. 36-38 (In Russian).

6. Maksimenko V.N., Zaytsev K.I., Chibikov A.V. Flash removal from welded joints of polyethylene pipes. Plasticheskie Massy, 1981, no. 12, pp. 30-31 (In Russian).

7. Shurayts A.L., Kargin V.Yu., Volnov Yu.N. Gazoprovody iz polimernykh materialov: Posobie po proektirovaniyu, stroitelstvu i ekspluatatsii [Gas Pipelines from Polymeric Materials: 
Manual for Design, Construction, and Operation]. Saratov, Volga - XXI vek Publ., 2007, 612 p. (In Russian).

8. Danzanova E.V. Questions of the control of quality welded joining the polyethylene pipes for gas main. Scientific and Technical Journal "Petroleum Engineering (Neftegazovoe Delo)", 2009, no. 1. (In Russian). Available at: http://ogbus.ru/authors/Danzanova/Danzanova_1.pdf

9. Gerasimov A.I., Danzanova E.V., Botvin G.V. A method for testing the strength of welded butt joints of polymer pipes, $R F$ Patent 2465560, 2012. (In Russian).

10. GOST 11262-80. Plastmassy. Metod ispytaniya na rastyazhenie [Plastics. Tensile test method: Russian State Standards]. Moscow, Izd-vo Standartov Publ., 1986, 16 p.

11. Ammosova O., Starostin N., Gerasimov A. Svarka polietilenovykh trub pri nizkikh klimaticheskikh temperaturakh [Welding of Polyethylene Pipes at Low Climatic Temperatures]. Saarbrucken, Germany, LAP Lambert Academic Publishing GmbH \& Co., 2012, 96 p. ISBN: 978-3-8473-7400-8. (In Russian). 
Подана в журнал: 11.10 .2018

УДК 620.172.21

DOI: $10.17804 / 2410-9908.2019 .2 .006-015$

\title{
МЕТОД КОНТРОЛЯ КАЧЕСТВА СВАРНЫХ СОЕДИНЕНИЙ ПОЛИМЕРНЫХ ТРУБ
}

\author{
А. И. Герасимов ${ }^{\text {a) }}$ Е. В. Данзанова ${ }^{\text {б)* }}$ \\ Федеральное государственное бюджетное учреждение науки Институт проблем нефти и газа СО РАН, \\ ул. Октябрьская, 1, 677980, г. Якутск, Российская Федерация \\ a) (iD https://orcid.org/0000-0003-4114-9955 gerasimov2509@ rambler.ru; \\ б) (iD https://orcid.org/0000-0002-3445-0961 dhv4071@mail.ru \\ *Ответственный автор. Электронная почта: dhv4071@ mail.ru \\ Адрес для переписки: ул. Октябрьская, 1, 677980, г. Якутск, Российская Федерация \\ Тел.: +7 (4112) 35-72-93
}

В настоящее время существующими в действующих нормативных документах методами контроля качества сварных соединений полиэтиленовых труб невозможно количественно оценить прочность по шву. В данной работе приводятся исследования по разработке методики для количественной оценки прочности сварных соединений, полученных при различных условиях сварки. Получены данные по влиянию изменения одного из параметров сварки на разрушающее напряжение получаемых соединений.

Ключевые слова: полиэтиленовая труба, сварное соединение, испытание на растяжение, параметр сварки, разрушающее напряжение.

\section{1. Введение}

При строительстве трубопроводов из полимерных труб основным способом их соединения является сварка нагретым инструментом встык (НИВ) [1]. Контроль качества сварки проводится существующими в действующих нормативных документах разрушающими и неразрушающими методами испытаний. Методы испытаний в свою очередь делятся на обязательные и специальные. Специальные методы испытаний проводятся для подтверждения результатов обязательных методов, а также для углубленных исследований. К обязательным методам испытаний относятся внешний осмотр, испытания на осевое растяжение, ультразвуковой контроль, пневматические испытания. В перечень специальных методов входят следующие испытания: испытание на статический изгиб, испытание при постоянном внутреннем давлении, испытание на длительное растяжение [2].

Анализ принятых в действующих нормативных документах методов оценки качества сварных соединений показывает, что ни одно из приведенных выше испытаний не дает количественную оценку прочности сварного соединения по стыку сварки, а некоторые авторы также высказывают мнение о невысокой информативности испытаний и низкой достоверности получаемых при этом результатов [3-6].

При внешнем осмотре по замеченным изменениям в размерах грата, его формы, цвета или равномерности распределения можно определить, какие из параметров сварки имели отклонения от установленных норм, или установить нарушение других условий сварки. В то же время визуальная оценка внешнего вида шва не достаточно эффективна, так как на формирование грата оказывают влияние температура окружающей среды и свойства самого материала. Испытание на осевое растяжение является пока основным и единственным оперативным методом оценки качества сварных соединений. Однако критерием определения качества сварного соединения, выполненного сваркой встык, является характер разрушения 
образцов. Известно, что при испытаниях на растяжение разрушение происходит в большинстве случаев по основному материалу, а не по сварному шву [5]. Ультразвуковой контроль, пневматические испытания, испытания на статический изгиб, испытания при постоянном внутреннем давлении, испытания на длительное растяжение являются с количественной стороны недостаточно информативными. Так, с помощью ультразвукового контроля должны выявляться внутренние дефекты типа несплавлений, трещин, отдельных или цепочек (скоплений) пор, включений площадью более 1,5 мм² [7]. Пневматические же испытания соединений производятся вместе с испытаниями всего ПЭ трубопровода на прочность и герметичность при внутреннем давлении воздуха. При испытании на статический изгиб определяется угол изгиба образца, при котором появляются первые признаки разрушения. Результаты испытания считаются положительными, если испытываемые образцы выдерживают без разрушения и появления трещин изгиб на угол не менее $160^{\circ}$. Ранее было установлено, что результат таких испытаний положительный даже в случае сварных соединений, выполненных с грубыми нарушениями технологического режима сварки [8]. При испытаниях при постоянном внутреннем давлении результаты испытаний считаются положительными, если все испытуемые образцы не разрушились до истечения контрольного времени при нормальной и повышенной температурах или разрушился один из образцов, которые тоже не дают количественную характеристику прочности сварного шва. В настоящее время наиболее информативным является испытание на длительное растяжение в активной среде, которое предусмотрено международным стандартом ISO 13952 и инструкцией DVS 2203-4 немецкого союза сварщиков [7]. Недостатком метода является то, что при испытаниях фиксируется время до разрушения, и количественно определить прочность сварного соединения по месту сплавления невозможно.

Целью работы является разработка методики количественной оценки прочности по шву сварных стыковых соединений полимерных труб и на его основе проведение контроля качества сварки.

\section{2. Методика проведения исследований}

Технологический процесс сварки нагретым инструментом встык полимерных труб представлен на рис. 1. После подготовки труб и деталей к сварке (очистка, сборка, центровка, механическая обработка торцов, проверка совпадения торцов и зазора в стыке) производится сварка стыка (оплавление, нагрев торцов, удаление нагретого инструмента, осадка стыка, охлаждение соединения). Основными параметрами сварки нагретым инструментом встык являются следующие: температура нагретого инструмента $T_{\mathrm{H}}$, продолжительность оплавления $t_{\text {оп }}$ и нагрева $t_{\mathrm{H}}$, давление нагретого инструмента на торцы при оплавлении $P_{\text {оп }}$ и нагреве $P_{\mathrm{H}}$, продолжительность технологической паузы между окончанием нагрева и нача-

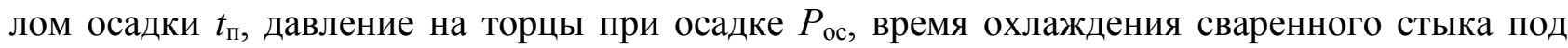
давлением осадки $t_{\text {охл }}[2]$.

При испытаниях на осевое растяжение образцов, вырезанных из основного материала полиэтиленовой трубы, прочность варьируется от 20 до 25 МПа в зависимости от производителя. Известно, что прочность сварного соединения при соблюдении всех требований сварки не ниже прочности основного материала трубы. Однако при стандартных испытаниях на осевое растяжение разрушение, как правило, происходит по основному материалу за счет увеличенной площади поперечного сечения образца сварного шва за счет образования грата в процессе сварки. Суть разработанной методики заключается в приравнивании исследуемой площади сварки к площади основного материала образца-лопатки для испытаний [9]. Это достигается следующим образом. Для исследуемого сварного стыкового соединения полиэтиленовой трубы заранее изготавливались шаблоны из тонкого материала с низкой теплопроводностью, например из листа писчей бумаги, препятствующего свариванию всей площади торцов трубы. Вырез для сваривания торцов трубы располагался так, чтобы в вырезан- 
ных образцах-лопатках площади сваренных участков были равными друг другу, а по величине - равными или не бо́льшими, чем сечение рабочей части основного материала образцалопатки. В процессе сварки после удаления нагревательного инструмента во время технологической паузы вставлялся шаблон. Затем осадка и охлаждение сварного соединения производились с наличием шаблона (рис. 2). Через 24 ч после сварки изготавливались образцылопатки типа 2 , с длиной рабочей части образцов $60 \pm 0,5$ мм и шириной $10 \pm 0,5$ мм по ГОСТ 11262 [10] равномерно по периметру шва в количестве не менее пяти штук так, чтобы область сварки находилась на середине образца-лопатки, что легко выполнить, ориентируясь по краям вставленного шаблона из белого листа бумаги. Испытания на растяжение образцовлопаток производили согласно ГОСТ 11262 на универсальной разрывной машине UTS20K при скорости движения захватов 25 мм/мин, разрушение происходило по месту сплавления сварного соединения (рис. 3). Обработку результатов испытаний проводили принятыми методами, т. е. из диаграммы «нагрузка-деформация» определяли разрушающую нагрузку в момент разрыва образца. Разрушающее напряжение рассчитывалось относительно фактической площади в момент разрушения образца. Таким образом, можно получить количественную оценку прочности сварного соединения по стыку.

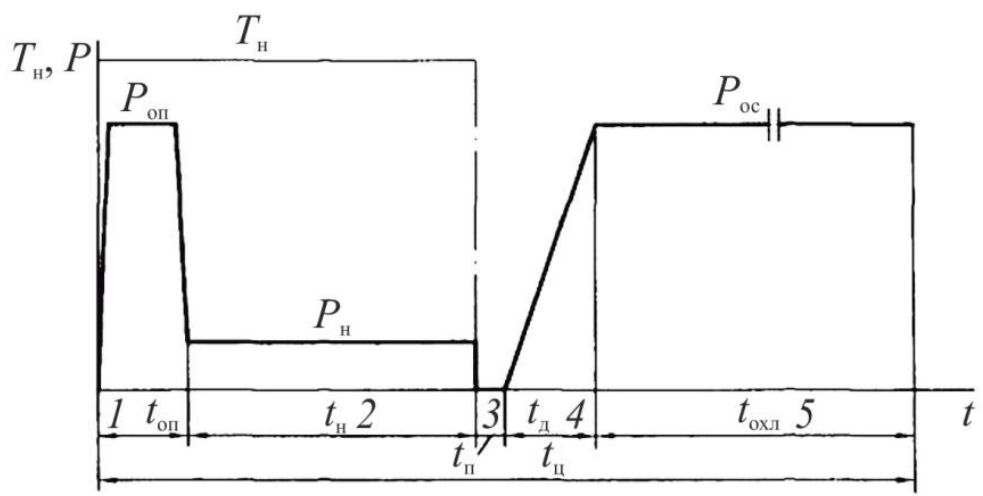

$a$

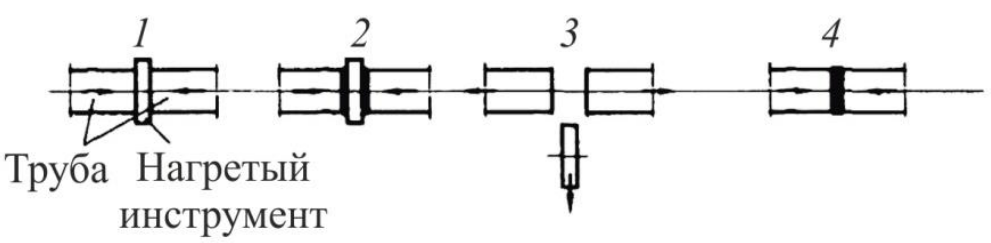

6

Рис. 1. Циклограмма процесса сварки встык нагретым инструментом труб из полиэтилена [2]: $a$ - диаграмма изменения во времени $(t)$ давления на торцах $(P)$ и температуры нагретого инструмента $\left(T_{\mathrm{H}}\right) ; \sigma$ - последовательность протекания процесса сварки; 1 - оплавление торцов; 2 - нагрев концов труб; 3 - вывод нагретого инструмента (технологическая пауза); 4, 5 - осадка и охлаждение стыка

Контроль качества сварки данной методикой проводился на сварных соединениях полиэтиленовых труб ПЭ80 SDR11 63×5,8. В исследованиях использовалась машина для сварки встык нагревательным элементом ROWELD P160B фирмы ROTHENBERGER (Германия). Исходя из инструкции по эксплуатации данной сварочной машины для полиэтиленовой трубы ПЭ80 SDR11 63×5,8 за базовые были приняты следующие технологические параметры: давление при осадке $P_{\text {oc }}=4,4$ атм.; технологическая пауза $t_{\text {п }}=4$ с.; температура нагретого инструмента $T_{\mathrm{H}}=220{ }^{\circ} \mathrm{C}$; в вемя нагрева $t_{\mathrm{H}}=58 \mathrm{c}$; давление при нагреве $P_{\mathrm{H}}=0,6$ атм. Сварка производилась при комнатной температуре 
$\left(23^{\circ} \mathrm{C}\right)$ с изменением одного из приведенного параметра с сохранением остальных. Результаты испытаний на растяжение приведены на рис. 4-8. Зеленым цветом обозначены соответствующие нормативные значения параметров сварки для данного типоразмера полиэтиленовой трубы.

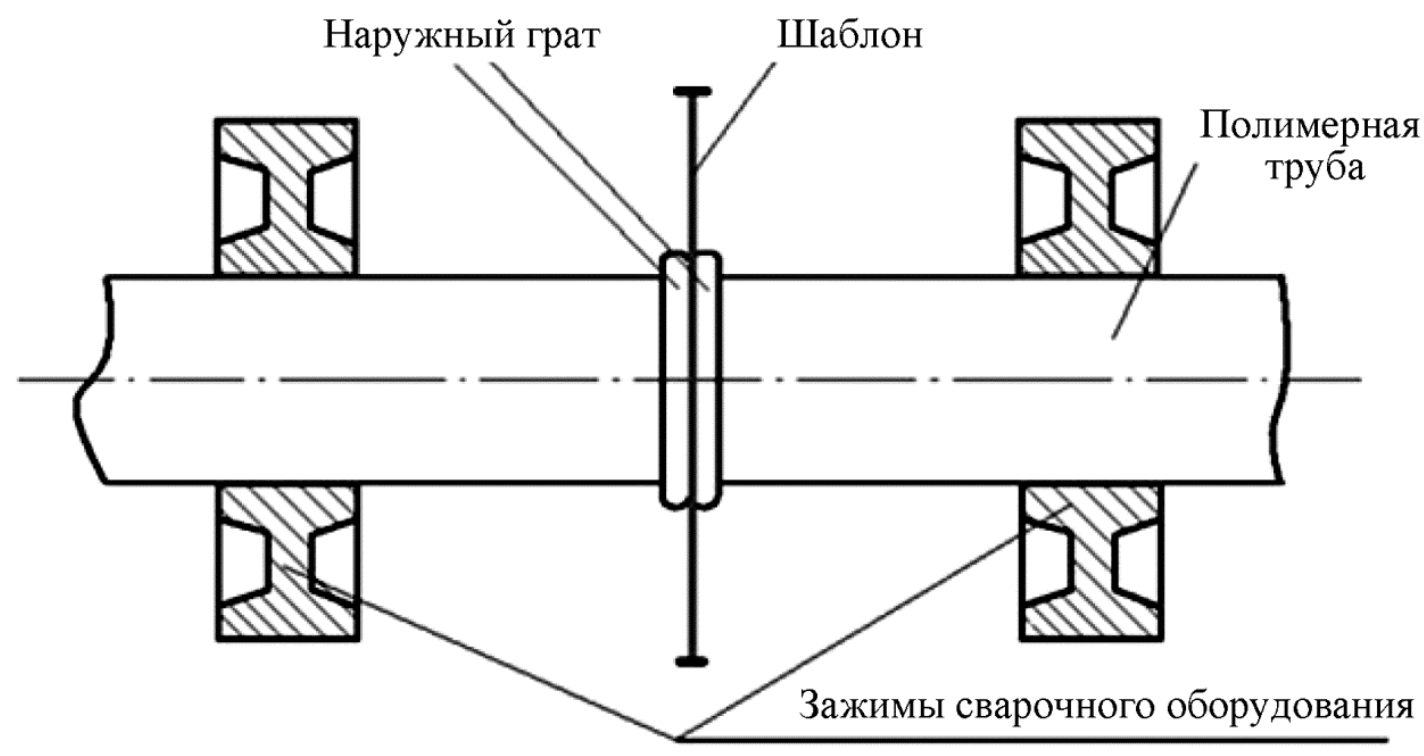

Рис. 2. Установка шаблона в процессе сварки полимерных труб

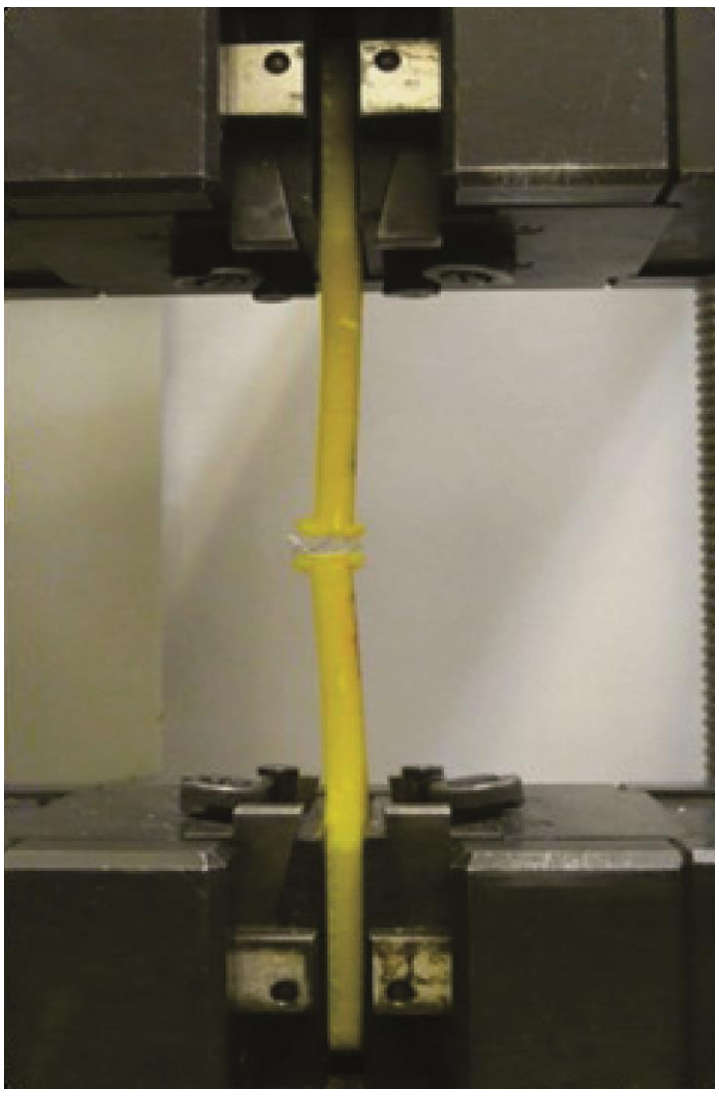

Рис. 3. Разрушение образца по сварному шву при растяжении 


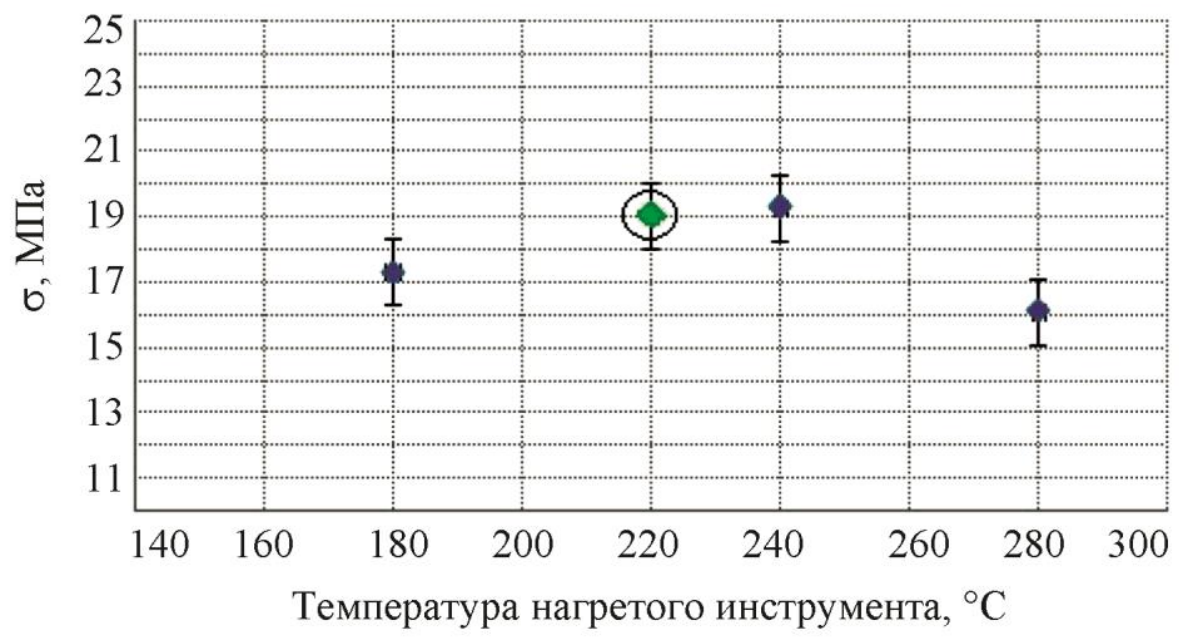

Рис. 4. Разрушающее напряжение сварных соединений, полученных при различных значениях температуры нагретого инструмента, $T_{\text {н }}$

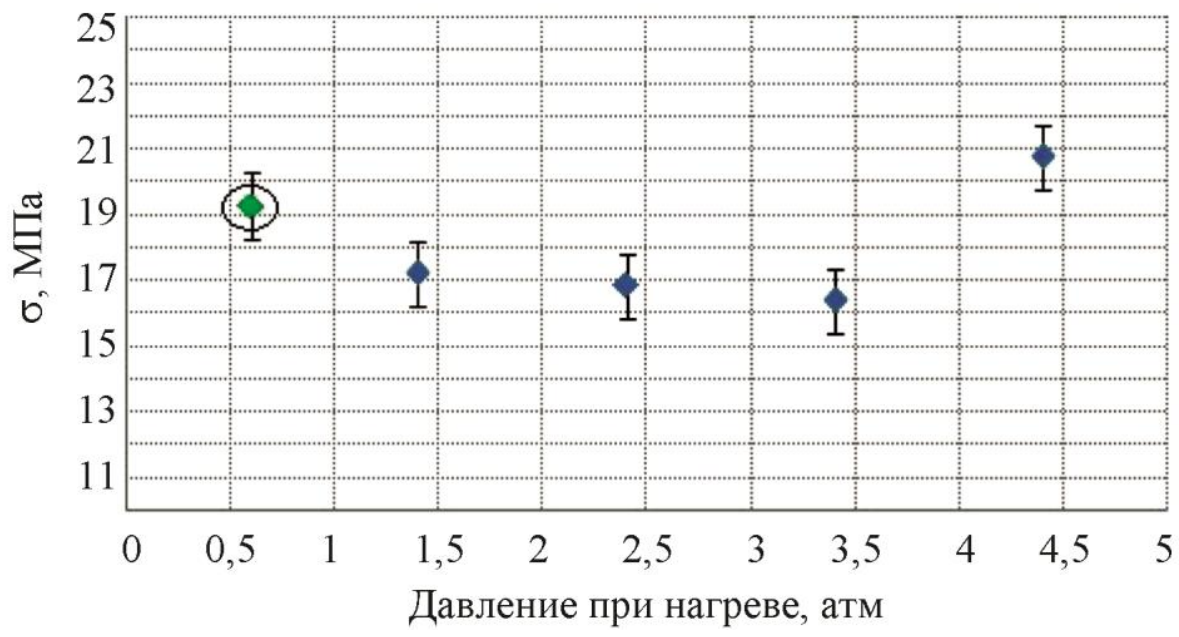

Рис. 5. Разрушающее напряжение сварных соединений при различных давлениях при нагреве торцов свариваемых труб, $P_{\text {н }}$

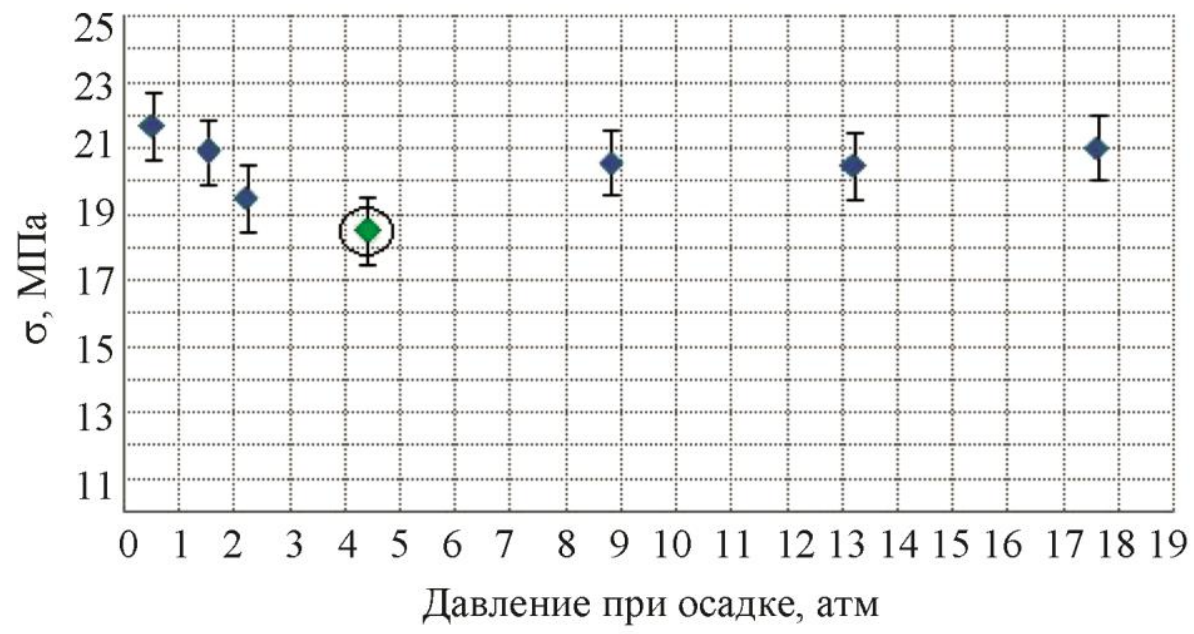

Рис. 6. Разрушающее напряжение сварных соединений, полученных при различных давлениях при осадке, $P_{\text {ос }}$ 


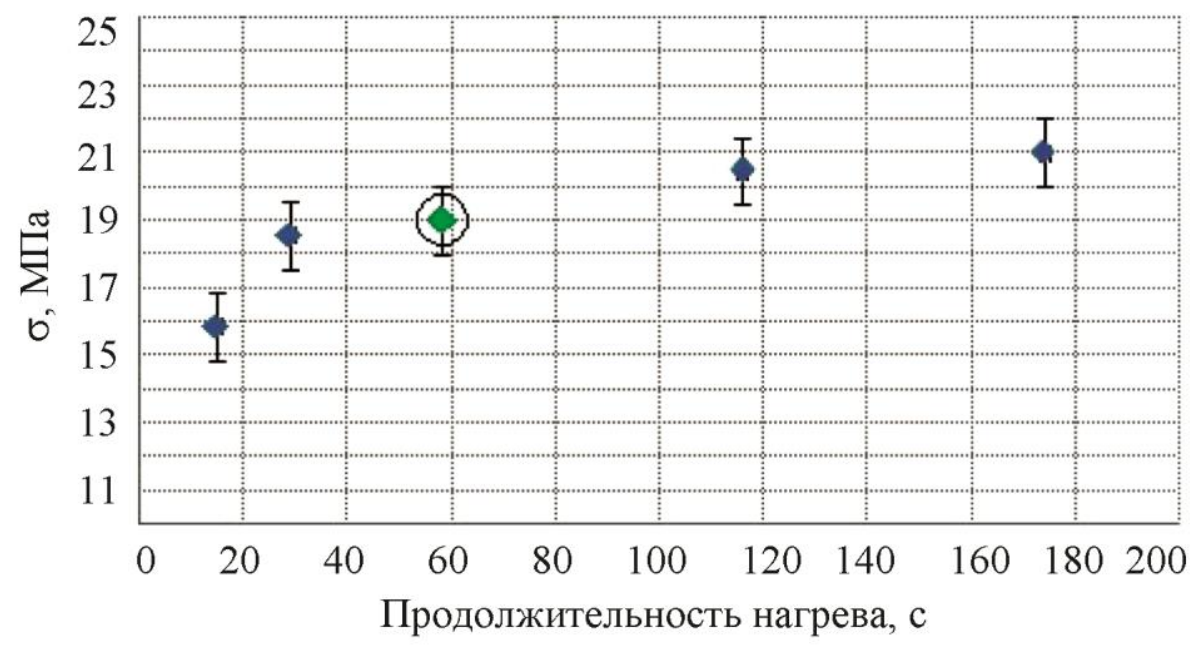

Рис. 7. Разрушающее напряжение в зависимости от продолжительности нагрева торцов свариваемых труб, $t_{\mathrm{H}}$

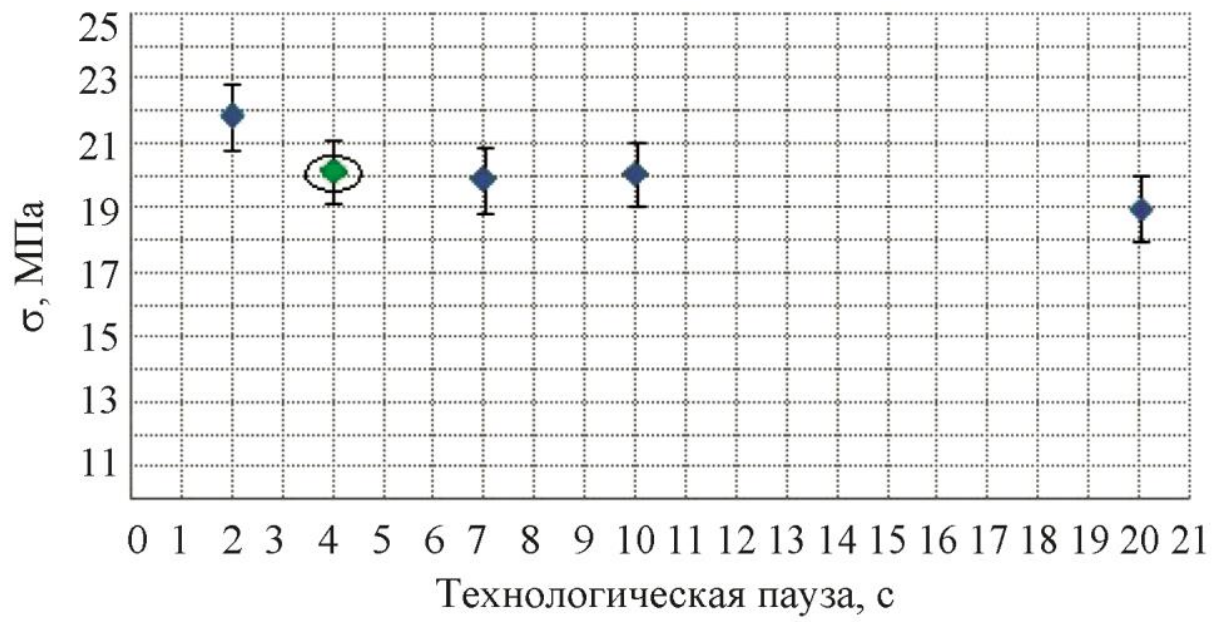

Рис. 8. Разрушающее напряжение сварных соединений в зависимости от продолжительности технологической паузы, $t_{\text {п }}$

\section{3. Результаты исследований и их обсуждение}

При сохранении остальных параметров наибольшая прочность получается при температуре нагретого инструмента $220-240{ }^{\circ} \mathrm{C}$ (рис. 4). Повышение давления при нагреве уменьшает прочность, однако при давлении нагрева, равном давлению при осадке, получается увеличение разрушающего напряжения сварного соединения по стыку (рис. 5). Этот факт является очень интересным и по этому направлению будут дополнительные исследования. В то же время очень странным является наименьшая величина прочности сварного шва при рекомендованном значении давления при осадке - 4,4 атм. (рис. 6). Увеличение продолжительности нагрева приводит к увеличению прочности, что, видимо, объясняется увеличением площади грата (рис. 7). Увеличение продолжительности технологической паузы в 2-4 раза при комнатной температуре для данного типоразмера полиэтиленовой трубы не приводит к снижению прочности сварного шва (рис. 8). По приведенным снимкам с тепловизора (рис. 9) в различное время после удаления нагретого инструмента видно, что даже на 10-й секунде температура поверхности торца трубы превышает температуру плавления полиэтилена. Известно, что градиент температуры полиэтилена на 1 мм глубины равен $50{ }^{\circ} \mathrm{C}$ [11]. А это значит, что температура глубинных слоев торца трубы после оттеснения поверхностного материала в грат еще выше, чем и объясняется высокая прочность стыка сварки при больших значениях технологической паузы. 

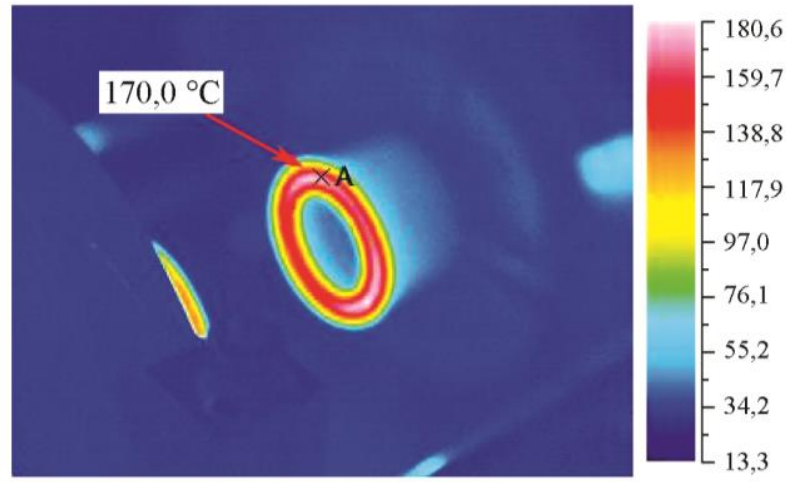

$t_{\Pi}=2 \mathrm{c}$
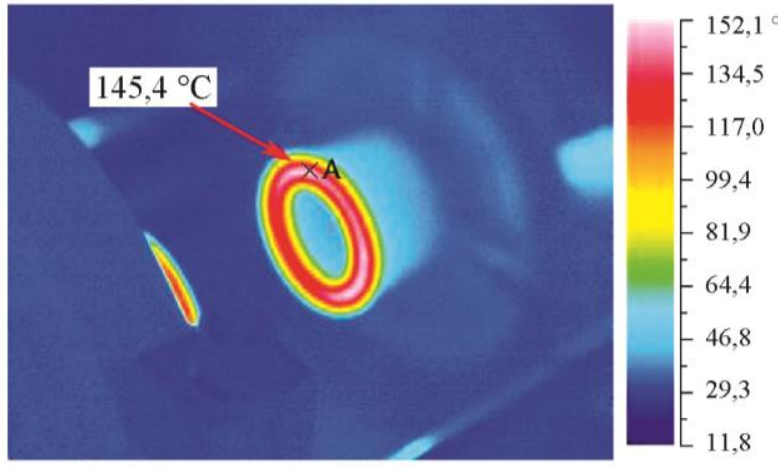

$t_{\Pi}=10 \mathrm{c}$

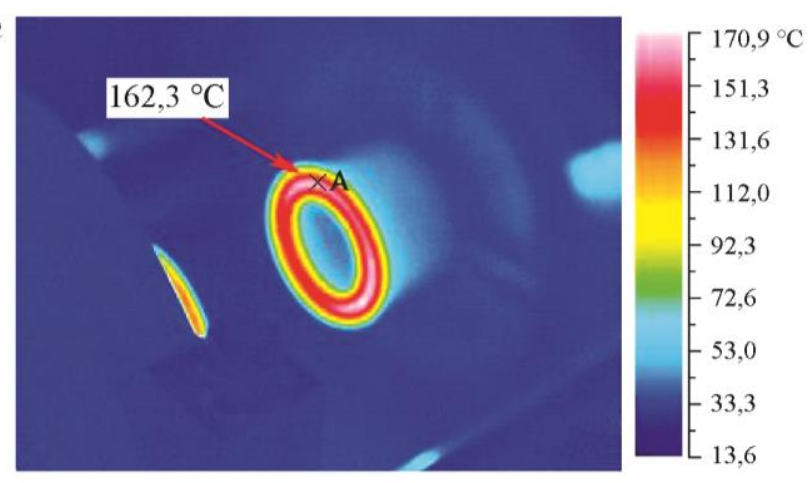

$t_{\Pi}=4 \mathrm{c}$

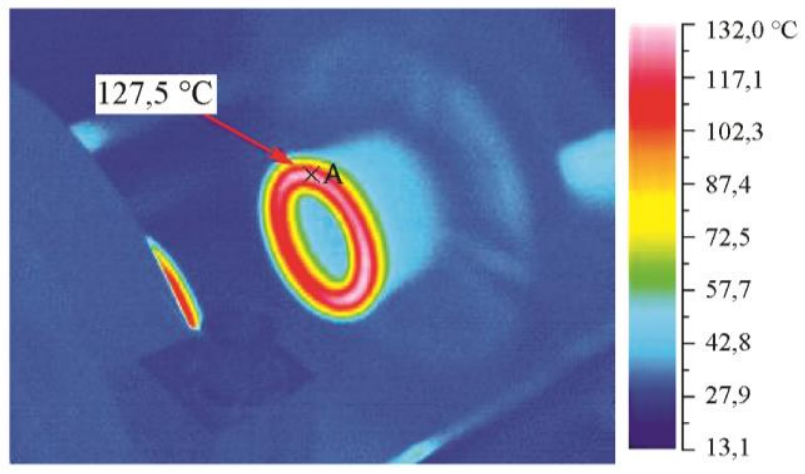

$t_{\Pi}=20 \mathrm{c}$

Рис. 9. Температура на торце полиэтиленовой трубы во время технологической паузы

\section{4. Заключение}

Разработан метод количественной оценки прочности стыкового сварного соединения полимерной трубы по стыку, с помощью которого можно проводить контроль качества сварки при выборе наилучших технологий. Показано, что увеличение технологической паузы в 2-3 раза не приводит к существенному уменьшению прочности сварного соединения полиэтиленовой трубы ПЭ80 SDR11 63×5,8. Значительное сокращение времени остывания сварного шва под давлением осадки не влияет на прочность по стыку сварного соединения полиэтиленовых труб. Разработанную методику испытаний можно использовать при оценке качества сварки.

\section{Благодарность}

Работа выполнена по Госзаданию ФАНО РФ 0377-2016-0004.

\section{Литература}

1. Кораб Г. Н., Адаменко А. А., Репа В. П. Повышение надежности сварных соединений пластмассовых труб, выполненных нагретым инструментом встык // Автоматическая сварка. 1984. - № 4. - C. 64-65.

2. СП 42-103-2003. Проектирование и строительство газопроводов из полиэтиленовых труб и реконструкция изношенных газопроводов / взамен СП 42-101-96, СП 42-103-97, СП 42-105-99; введ. в действие с 27.11.2003. - М. : Полимергаз, ФГУП ЦПП, 2004. - 86 с. : ил.

3. Адаменко А. А., Кораб Г. Н., Тарногородский В. П. Повышение качества соединений пластмассовых труб, выполненных контактно-тепловой сваркой // Автоматическая сварка. 1983. - № 3. - C. 51-53. 
4. Аксенова Г. В., Кашковская Е. А. Контроль качества сварных соединений труб из полиэтилена по характеру разрушения при осевом растяжении // Автоматическая сварка. 1980. - № 2. - С. 61-63.

5. Красников М. А., Пожалов Ю. В., Соколов В. А. Механика разрушения стыковых сварных соединений полиэтиленовых труб при испытаниях на растяжение статической нагрузкой // Полимергаз. - 2011. - № 1. - С. 36-38.

6. Максименко В. Н., Зайцев К. И., Чибиков А. В. Удаление грата со сварных швов полиэтиленовых труб // Пластические массы. - 1981. - № 12. - С. 30-31.

7. Шурайц А. Л., Каргин В. Ю., Вольнов Ю. Н. Газопроводы из полимерных материалов: Пособие по проектированию, строительству и эксплуатации. - Саратов : Изд-во Журнал «Волга - XXI век», 2007. - 612 с.

8. Данзанова Е. В. Вопросы контроля качества сварных соединений полиэтиленовых труб для газопроводов // Электронный научный журнал «Нефтегазовое дело» http://www.ogbus.ru/ /authors/Danzanova/Danzanova_1.pdf2009. - 2009. - C. 1-8.

9. Способ испытания прочности сварного стыкового соединения полимерных труб : пат. 2465560 Рос. Федерация / Герасимов А. И., Данзанова Е. В., Ботвин Г. В., Ин-т проблем нефти и газа СО РАН. - № 2011115737/28 ; заявл. 20.04.2011 ; опубл. 29.10.2012, Бюл. № 30.

10. ГОСТ 11262-80. Пластмассы. Метод испытания на растяжение / введ. 1980-12-01. - М. : Изд-во стандартов, 1986. - 16 с. : ил.

11. Аммосова О., Старостин Н., Герасимов А. Сварка полиэтиленовых труб при низких климатических температурах. - Saarbrucken, Germany : LAP LAMBERT Academic Publishing GmbH \& Co., 2012. - 96 c. - ISBN: 978-3-8473-7400-8. 